\title{
Szeged Matrix Property Indices as Descriptors to Characterize Fullerenes
}

\author{
Lorentz JÄNTSCHI ${ }^{1,2}$ and Sorana D. BOLBOACA $\breve{A}^{3, *}$ \\ ${ }^{1}$ Technical University of Cluj-Napoca, Department of Physics and Chemistry, 103-105 Muncii Bldv., \\ RO-400641, Cluj-Napoca, Romania \\ ${ }^{2}$ Babeş-Bolyai University, Doctoral Studies - Chemistry, 11 Arany Janos str., RO-400028, Cluj-Napoca, \\ Romania \\ ${ }^{3}$ Iuliu Haţieganu University of Medicine and Pharmacy, Department of Medical Informatics and Biostatistics, 6 \\ Louis Pasteur str., RO-400349, Cluj-Napoca, Romania
}

\begin{abstract}
Fullerenes are class of allotropes of carbon organized as closed cages or tubes of carbon atoms. The fullerenes with small number of atoms were not frequently investigated. This paper presents a detailed treatment of total strain energy as function of structural feature extracted from isomers of $\mathrm{C}_{40}$ fullerene using Szeged Matrix Property Indices (SMPI). The paper has a two-fold structure. First, the total strain energy of $\mathrm{C}_{40}$ fullerene isomers (40 structures) was linked with SMPI descriptors under two scenarios, one which incorporate just the SMPI descriptors and the other one which contains also five calculated properties (dipole moment, scf-binding-energy, scf-core-energy, scf-electronic-energy, and heat of formation). Second, the performing models identified on $\mathrm{C}_{40}$ fullerene family or the descriptors of these models were used to predict the total strain energy on $\mathrm{C}_{42}$ fullerene isomers. The obtained results show that the inclusion of properties in the pool of descriptors led to the reduction of accurate linear models. One property, namely scf-binding-energy proved a significant contribution to total strain energy of $\mathrm{C}_{40}$ fullerene isomers. However, the top-three most performing models contain just SMPI descriptors. A model with four descriptors proved most accurate model and show fair abilities in prediction of the same property on $\mathrm{C}_{42}$ fullerene isomers when the approach considered the descriptors identified on $\mathrm{C}_{40}$ as the predicting descriptors for $\mathrm{C}_{42}$ fullerene isomers.
\end{abstract}

Keywords: nano structure-property relationship; $\mathrm{C}_{40}$ fullerene; $\mathrm{C}_{42}$ fullerene; Szeged Matrix Property Indices (SMPI).

\section{Introduction}

Fullerenes are class of allotropes of carbon organized as closed cages or tubes of carbon atoms. Fullerenes received attention from the researchers all over the word and led to the synthesis of new compounds [1-4] and identification of different applications due to their hardness, high electron affinity, increased incident light intensity, and biological activities [5-7].

$\mathrm{C}_{40}$ is one of the small fullerene and several symmetries of these cages such as $\mathrm{D}_{5 \mathrm{~d}}[8,9], \mathrm{D}_{4 \mathrm{~h}}[10$, 11], $D_{2 \mathrm{~d}}[9], \mathrm{D}_{2 \mathrm{~h}}$ [12] were identified and studied. Further, $a b$ initio studies on stability of $\mathrm{C}_{40}$ fullerene were performed $[13,14] \mathrm{C}_{40}$ fullerene has 40 known isomers. Dinca et al. conducted a theoretical study on the $\mathrm{C}_{40}$ isomers and showed that pentagon valence parameter correlates well with heat of formation as a measure of thermodynamic stability [7]. Halogenated $\mathrm{C}_{40}$ cage has been identified as a good candidate for hydrogen storage [15] while all $\mathrm{C}_{40}$ fullerene isomers were found to be highly aromatized at the polyvalent anionic states [16].
A nano-quantitative structure-property relationship modeling on $\mathrm{C}_{42}$ fullerene isomers showed the ability of Szeged Matrix Property Indices (SMPI [17]) as structural descriptors to fit the total strain energy [18]. The aim of this study was to assess the estimation degree for total strain energy derived in the context of continuum elasticity theory on a pool of structural descriptors and respectively structural and property descriptors. Furthermore, the prediction abilities of the most accurate models were assessed on $\mathrm{C}_{42}$ fullerene isomers in the context of the same property.

\section{Materials and methods}

\subsection{Data sets}

Data and the values of the total strain energy (continuum elasticity) are online available and were taken from the following addresses:

URL:

http://nanotube.msu.edu/fullerene/fullerene.php?C=40

URL:

http://nanotube.msu.edu/fullerene/fullerene.php?C=42

\footnotetext{
* Corresponding author: phone: +40750774506; e-mail: sbolboaca@umfcluj.ro
} 
Forty isomers of $\mathrm{C}_{40}$ fullerene and forty-five isomers of $\mathrm{C}_{42}$ fullerene were included in the study.

\subsection{Regression analysis}

The structures of $\mathrm{C}_{40}$ and $\mathrm{C}_{42}$ fullerene isomers were downloaded as *.xyz files and the molecules were included in the analysis as downloaded. The geometry of the investigated fullerene was based on the geometry of the structures in the Yoshida's Fullerene Library and re-optimized using Dreidinglike force-field [19]. The procedure presented in Table 1 was applied on both investigated sets.

Table 1. Preliminary operations apply to $\mathrm{C}_{40}$ and $\mathrm{C}_{42}$ isomers

\begin{tabular}{|c|c|c|c|c|}
\hline Step & What? & $\begin{array}{l}\text { Input } \\
\text { files }\end{array}$ & $\begin{array}{c}\text { Output } \\
\text { files }\end{array}$ & Why? \& Program and what does it do \\
\hline 1 & $\begin{array}{l}\text { Converting } \\
\text { files }\end{array}$ & $* . x y z$ & *.mol & $\begin{array}{l}\text { *.xyz files do not contain bond information \& Spartan program (automatically detect } \\
\text { bonds and connect the atoms) }\end{array}$ \\
\hline 2 & $\begin{array}{l}\text { Converting } \\
\text { files }\end{array}$ & *.mol & *.hin & $\begin{array}{l}\text { *.mol files do not contain partial charge information \& Babel program } \\
\text { (http://openbabel.org) was used to convert the *.mol files to HyperChem files } \\
\text { (http://www.hyper.com/) }\end{array}$ \\
\hline 3 & $\begin{array}{c}\text { Partial charges } \\
\text { calculation }\end{array}$ & *.hin & *.hin & $\begin{array}{c}\text { SMPI [17] needs partial charges in order to provide a full family of structure } \\
\text { descriptors \& HyperChem/AM1/SinglePoint [20] was used }\end{array}$ \\
\hline 4 & $\begin{array}{c}\text { Structure } \\
\text { descriptors }\end{array}$ & *.hin & $* . \mathrm{txt}$ & $\begin{array}{c}\text { The tool http://l.academicdirect.org/Chemistry/SARs/SMPI/ \& fast, simple and } \\
\text { provide descriptors for all molecules at once }\end{array}$ \\
\hline
\end{tabular}

The pool of structural descriptors (scenario 1) and of structural and property descriptors (scenario 2; properties: dipole moment, scf-binding-energy, scfcore-energy, scf-electronic-energy, and heat of formation) was used as raw data in estimation of most accurate structure-property and structure-propertyproperty models on $\mathrm{C}_{40}$ data set, respectively.

The files containing the raw data from both scenarios entered separately into the regression analysis. The analysis was conducted using classical approach of multiple linear regressions, when sum of squares of residuals from vertical offsets were minimized:

$$
\mathrm{Y} \sim \hat{\mathrm{Y}}=\mathrm{a}_{0}+\Sigma_{1 \leq \mathrm{i} \leq \mathrm{m}} \mathrm{b}_{\mathrm{i}} \mathrm{X}_{\mathrm{i}}
$$

or

$$
\begin{gathered}
\mathrm{Y} \sim \hat{\mathrm{Y}}=\Sigma_{1 \leq \mathrm{i} \leq \mathrm{m}} \mathrm{b}_{\mathrm{i}} \mathrm{X}_{\mathrm{i}} \text { when } \mathrm{a}_{0} \text { is not significantly } \\
\text { different by } 0
\end{gathered}
$$

where $Y$ is the total strain energy (dependent variable), $X_{i}$ is the structural or property descriptor $\left\{X_{i} ; 1 \leq \mathrm{i} \leq \mathrm{m}\right\}$ (independent variables), $m$ is the number of independent variables in the model, $a_{0}$ is the intercept of the model, $b_{i}$ is the slope.

The coefficients of the regression model were obtained by minimizing the residuals:

$$
\mathrm{SSr}=\Sigma_{1 \leq \mathrm{j} \leq \mathrm{n}}\left(\mathrm{Y}_{\mathrm{j}}-\hat{\mathrm{Y}}_{\mathrm{j}}\right)^{2} \rightarrow \min .
$$

Systematic search for those descriptors able to explain the investigated continuum elasticity was conducted on simple and multiple regression analysis (up to four descriptors) on $\mathrm{C}_{40}$ dataset. The size of descriptors pools for identification of the most accurate models for each scenario is given in Table 2 . One program has been developed and implemented to filter the regressors (both structural descriptors and properties) based on their explanatory power (absolute values: $10^{-7}<\left|X_{i}\right|<10^{7}$ ), and association between the property as dependent variable and the regressors (for correlations (for all regressors): 0.001 $<r^{2}\left(X_{i}, Y\right), r^{2}\left(X_{i 1}, X_{i 2}\right)<0.999$, where $\mathrm{r}^{2}=$ determination coefficient). The number of filtered descriptors is given in Table 2.

Table 2. Size of the pools of regressors in the considered scenarios

\begin{tabular}{|c|l|l|c|}
\hline $\begin{array}{c}\text { Scena } \\
\text { rio }\end{array}$ & \multicolumn{1}{|c|}{ Data file } & $\begin{array}{c}\text { No. of } \\
\text { regressors }\end{array}$ & $\begin{array}{c}\text { Qualified } \\
\text { descriptors }\end{array}$ \\
\hline 1 & C40_data.txt & 1512 & 232 \\
\hline 2 & C40_datap.txt & $1517(1512+5)$ & $236(232+4)$ \\
\hline
\end{tabular}

An additional program was developed to systematically search for linear models (LM, with the dependent variable and among regressors). A huge number of regressions were tested $(125,991,255$ regressions only for the second scenario and only for the case of the search with four variables). Several special features were implemented in this program to assure a fast run and to provide useful information (see Table 3).

Table 3. Features of the program implemented to find linear models

\begin{tabular}{|l|l|}
\hline \multicolumn{1}{|c|}{ Feature } & \multicolumn{1}{|c|}{ Explanation } \\
\hline $\begin{array}{l}\text { The descriptors were stored into dynamic } \\
\text { arrays. }\end{array}$ & $\begin{array}{l}\text { Running the program for different dataset or scenario need the input } \\
\text { data of different sizes (see Table 2) }\end{array}$ \\
\hline $\begin{array}{l}\text { Two scenarios of output were implemented, } \\
\text { one in which regressions are listed only if has } \\
\text { higher } \mathrm{r}^{2} \text { value, and the other in which the } \\
\text { regressions are listed if have the } \mathrm{r}^{2} \text { value } \\
\text { higher than a given value. }\end{array}$ & $\begin{array}{l}\text { The scenario for listing only of the regression with higher } \mathrm{r}^{2} \text { works } \\
\text { very well in the testing of the association, but } \mathrm{r}^{2} \text { is not the only } \\
\text { criterion used to select the most accurate associations }\end{array}$ \\
\hline
\end{tabular}




\begin{tabular}{|c|c|}
\hline Fea & \\
\hline $\begin{array}{l}\text { When coefficients of regression are obtained, } \\
\text { n the same time are obtained their associated } \\
\text {-values (null hypothesis: the value of } \\
\text { oefficient is not significantly different by } \\
\text { ero) by calculating the inverse of the matrix } \\
\text { f the system. }\end{array}$ & $\begin{array}{l}\text { For two reasons: } \\
\div \quad \text { First, worth nothing to list a regression that has coefficients } \\
\text { with no statistical significance. } \\
\div \quad \text { Second, if specifically the intercept has no statistical } \\
\text { significance, in means that also the model with no intercept } \\
\text { should be tested for significance. }\end{array}$ \\
\hline $\begin{array}{l}\text { A modification of the classical formula } \\
\text { he calculation of the correlation coeffic } \\
\text { etween observed (Y) and estimated v } \\
\hat{Y} \text { ) was implemented. This method did } \\
\text { equire the calculation of the estimated va } \\
\text { or each molecule in the dataset. }\end{array}$ & $\begin{array}{l}\text { After obtaining of the coefficients, the determination coefficient } \\
\text { between observed (Y) and estimated value ( } \hat{Y}) \text { should be } \\
\text { calculated, to list or not the possible regression. But, the classical } \\
\text { formula requires need to calculate first the estimated values, which } \\
\text { is time consuming (complexity of } \mathrm{O}(\mathrm{n} \cdot \mathrm{m}) \text { order). This task is time } \\
\text { and resources consuming. The modification reduced the } \\
\text { complexity at } \mathrm{O}(\mathrm{m}) \text {. }\end{array}$ \\
\hline or c & \\
\hline
\end{tabular}

The program to find the SLR (simple linear regression) and MLR (multiple linear regression) models was run in the test mode, namely to list regressions only if an improvement in the determination coefficient exists.

The determination coefficient $\left(\mathrm{r}^{2}\right)$ was provided as an estimation parameter and determination coefficient in leave-one-out analysis $\left(\mathrm{Q}^{2}\right)$ as a parameter of internal validation of the model $[21,22]$.

\subsection{Assessment of the models}

The performances in estimation of the top-three models with highest goodness-of-fit were assessed using the measures presented in Table 4 [23-25].

Table 4. Statistics for assessment of the regression models

\begin{tabular}{|l|l|l|}
\hline \multicolumn{1}{|c|}{ Name } & Abbreviation & $\begin{array}{l}\text { Desired } \\
\text { value }\end{array}$ \\
\hline $\begin{array}{l}\text { Adjusted determination } \\
\text { coefficient }\end{array}$ & $\mathrm{r}^{2}$ adj & high \\
\hline $\begin{array}{l}\text { Ratio of variance } \\
\text { explained by the model }\end{array}$ & F-value & high \\
\hline Residual mean square & RMS & low \\
\hline $\begin{array}{l}\text { Average prediction } \\
\text { variance }\end{array}$ & APV & low \\
\hline $\begin{array}{l}\text { Average prediction } \\
\text { mean squared error }\end{array}$ & APMSE & low \\
\hline Mean absolute error & MAE & low \\
\hline Root mean square error & RMSE & < MAE \\
\hline $\begin{array}{l}\text { Mean obsolute } \\
\text { percentage error }\end{array}$ & MAPE & $\begin{array}{l}\text { closest to } \\
\text { zero }\end{array}$ \\
\hline $\begin{array}{l}\text { Standard error of } \\
\text { prediction }\end{array}$ & SEP & low \\
\hline $\begin{array}{l}\text { Relative error of } \\
\text { prediction }\end{array}$ & REP\% & low \\
\hline $\begin{array}{l}\text { Predictive } \\
\text { correlation coefficient in } \\
\text { training set }\end{array}$ & $\mathrm{Q}^{2}$ F1 & high \\
\hline
\end{tabular}

\subsection{Assessment of prediction power}

The prediction power of the most accurate models was assessed in two scenarios:

- The descriptors identified by the most accurate models on $\mathrm{C}_{40}$ dataset were used to predict the total strain energy for $\mathrm{C}_{42}$ dataset.

- The adjusted most accurate models obtained on $\mathrm{C}_{40}$ dataset were applied to $\mathrm{C}_{42}$ congeners.

The metrics used to assess the prediction ability [25] are presented in Table 5.

Table 5. Metrics for assessment of the prediction power of the models

\begin{tabular}{|c|c|c|}
\hline Name & $\begin{array}{c}\text { Abbreviat } \\
\text { ion }\end{array}$ & $\begin{array}{c}\text { Desired } \\
\text { value }\end{array}$ \\
\hline $\begin{array}{l}\text { Determination coefficient of } \\
\text { the prediction set }\end{array}$ & $\mathrm{r}_{\text {ext }}^{2}$ & high \\
\hline $\begin{array}{l}\text { Predictive square correlation } \\
\text { coefficient in external set }\end{array}$ & $\mathrm{Q}^{2} \mathrm{~F} 2$ & high \\
\hline External prediction ability & $\mathrm{Q}^{2} \mathrm{F3}$ & high \\
\hline $\begin{array}{l}\text { Root mean square error of } \\
\text { predicted }\end{array}$ & RMSEP & low \\
\hline \begin{tabular}{|l} 
Mean absolute error of \\
predicted
\end{tabular} & MAEP & low \\
\hline Percentage predictive error & $\%$ PredErr & low \\
\hline $\begin{array}{l}\text { Concordance correlation } \\
\text { coefficient } \\
\text { (http://services.niwa.co.nz/servi } \\
\text { ces/statistical/concordance) }\end{array}$ & $\mathrm{CCC}$ & high \\
\hline
\end{tabular}

\section{Results and Discussion}

\subsection{Estimation models}

The study conducted to identify the most accurate models able to estimate the total strain energy on the $\mathrm{C}_{40}$ isomers showed that 37 models proved accurate when just structural descriptors are considered as independent variables. In addition, when the pool of descriptors contained both structural and property 
descriptors, just 28 models are identified. The trends in regard of determination coefficient of the identified models obtained on both scenarios are presented in Figure 1. One property descriptor represented by 'scf-binding-energy' is the only property with significant contribution to the total strain energy on $\mathrm{C}_{40}$ dataset. Its contribution is observed from the first model until the sixteenth model in the second scenario (Figure 1) while the last twelve models in both scenarios are identical and contain only structural descriptors. Details on all 37 and respectively 28 models are given in Supplementary Material.
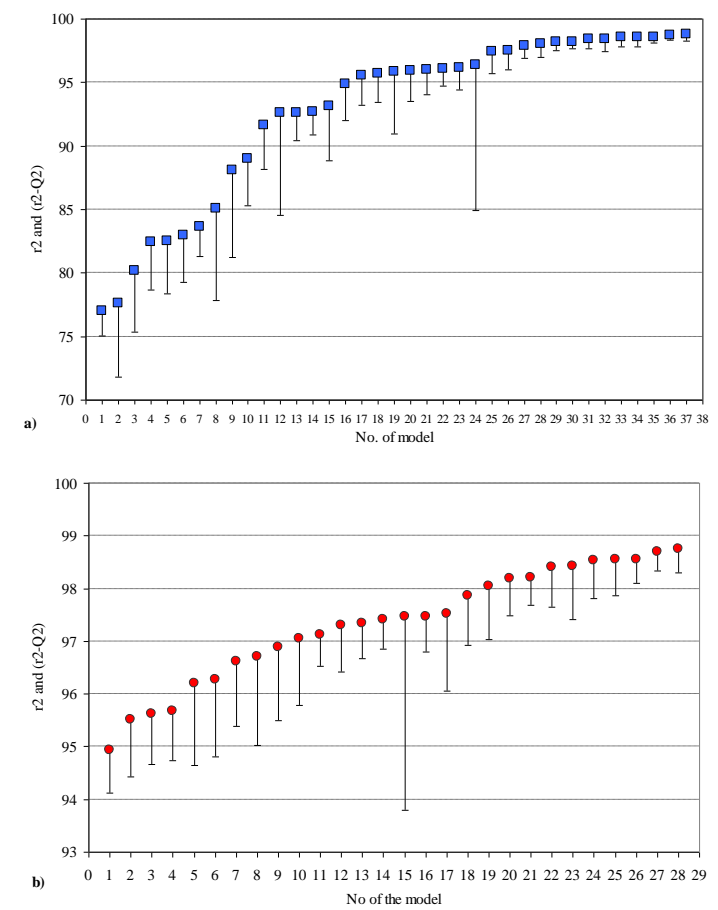

Figure 1. Improvement in regard of $\mathrm{r}^{2}(\%)$ with the increase of the number of descriptors in the models and the distance between $r^{2}$ and $Q^{2}$ (the ended line,

the smallest the better): a) first scenario ( 2

descriptors: model from 2 to $16 ; 3$ descriptors: models from 17 to $29 ; 4$ descriptors: models from 30 to 37$), \mathrm{b}$ ) second scenario (2 descriptors: model from 2 to $6 ; 3$ descriptors: models from 7 to $20 ; 4$ descriptors: models from 21 to 28). The first model is resulted from simple linear regression analysis and the contribution of property is significant,

leading to an improvement of determination coefficient from $77.02 \%$ (first scenario) to $94.94 \%$ (second scenario)

The investigated $\mathrm{C}_{40}$ dataset have some 'advantages' and 'disadvantages' in the regard of the applied methodology of analysis. All atoms are carbon atoms, so it is easy to do the research on such sample. Nevertheless, is not an advantage for SMPI, which operates at the level of the type of the atom too (take into account different atomic properties for different atom types). SMPI produces degenerated descriptors when all atoms are the identical, which reduces its explanatory power, so it is a disadvantage. All molecules have the same number of atoms, and all atoms have the same 'vertex degree' - e.g. number of bonds attached to it; this is another disadvantage, for a method based on topology, but not necessary of SMPI that works also at geometrical level. All bonds are of same type - aromatic bonds - and this is a disadvantage for SMPI (which degenerates again), since SMPI takes two topological approaches - one classical in which the topological distances are counted as the number of bonds, and another one in which the distance is counted as the inverse of the bond order.

Three models with high goodness-of-fit and small difference between goodness-of-fit and determination coefficient in leave-one-out analysis were assessed concerning their prediction abilities of the set of $\mathrm{C}_{42}$ congeners. The top-three models are given in $\mathrm{Eq}(1)-(3)$ :

$$
\begin{aligned}
& \hat{\mathrm{Y}}=2.50 \times 10^{3}+0.0010^{*} \mathrm{ImUGG} \\
& 6.23 \times 10^{5 * R J U G E-} \\
& 2.1762 * \text { IFEGE }+3.91 \times 10^{-4 *} * \text { IIEGA } \\
& \mathrm{r}^{2}=0.9856, \mathrm{r}_{\text {adj }}^{2}=0.9839 \text {, } \\
& \text { F-value }\left(\mathrm{p}=1.12 \times 10^{-31}\right)=598, \mathrm{Q}^{2}=0.9810 \\
& \hat{\mathrm{Y}}=2.44 \times 10^{3}-3.1038 * \mathrm{LMEGG} \quad- \\
& 6.20 \times 10^{5 * R J U G E-2.0521 * I F E G E} \\
& +3.90 \times 10^{-4} * \text { IIEGA } \\
& \mathrm{r}^{2}=0.9870, \mathrm{r}_{\text {adj }}^{2}=0.9855 \text {, } \\
& \text { F-value }\left(\mathrm{p}=1.78 \times 10^{-32}\right)=665, \mathrm{Q}^{2}=0.9833
\end{aligned}
$$$$
\hat{\mathrm{Y}}=2.5822 * \mathrm{IJUGE}+2.7106 * \text { IFUGE- }
$$

$3.0808 *$ IIUGE-0.5322*IIPTB

$\mathrm{r}^{2}=0.9876, \mathrm{r}_{\text {adj }}^{2}=0.9587$,

F-value $\left(\mathrm{p}=5.15 \times 10^{-33}\right)=714, \mathrm{Q}^{2}=0.9830$

where $\hat{Y}=$ estimated total strain energy; ImUGG, RJUGE, IFEGE, IIEGA, LMEGG, IJUGE, IFUGE, IIUGE, and IIPTB = SMPI structural descriptors; $r^{2}$ $=$ determination coefficient; $r^{2}{ }_{a d j}=$ adjusted determination coefficient; $\mathrm{F}$-value $=$ ratio of variance explained by the model; $\mathrm{p}=\mathrm{p}$-value associated to Fvalue $\mathrm{Q}^{2}=$ determination coefficient in leave-one-out analysis.

The models in $\mathrm{Eq}(1)-\mathrm{Eq}(3)$ considered a total number of nine SMPI descriptors, five of them linking electronegativity $[26,27]$ with the total strain energy, while other considered melting point temperature ('G' as the last letter in the descriptor name), atomic mass ('A') or atomic number ('B'). With one exception represented by IIPTB descriptor, all other descriptors considered the distance matrix calculated using topological distance ('G' as the fourth letter in the descriptors name). The third letter in the descriptors name refers the interaction effects matrix operating on the properties and on the distances matrices. The second letter is related with the value calculated in the interaction effect matrix as minimum or maximum ('m' respectively 'M' letter as 
second letter in the descriptor name), half$\operatorname{sum}\left(\mathrm{M}_{\mathrm{i}, \mathrm{j}} * \mathrm{M}_{\mathrm{j}, \mathrm{i}} * \mathrm{Ad}_{\mathrm{i}, \mathrm{j}}\right.$, where $\mathrm{M}_{\mathrm{i}, \mathrm{j}}=$ the $\mathrm{i}^{\text {th }}$ and $\mathrm{j}^{\text {th }}$ element on matrix, $\mathrm{M}_{\mathrm{j}, \mathrm{i}}=$ the $\mathrm{j}^{\text {th }}$ and $\mathrm{i}^{\text {th }}$ element on matrix, and $A d_{i, j}=$ the $i^{\text {th }}$ and $j^{\text {th }}$ element on adjacency matrix) (' $F^{\prime}$ letter), half-sum $\left(\mathrm{M}_{\mathrm{i}, \mathrm{j}}\right) \quad$ ('I' letter), or half$\operatorname{sum}\left(\mathrm{M}_{\mathrm{i}, \mathrm{j}} * \mathrm{M}_{\mathrm{j}, \mathrm{i}}\right) \quad$ ('J' letter). The first letter in the descriptor name is related with the linearization operator.

The analysis of the results revealed that the $\operatorname{Eq}(2)$ model is the one with both higher adjusted determination coefficient and higher determination coefficient in leave one-out analysis. Just one measure associated to the residual errors, named mean absolute error indicate that model from $\operatorname{Eq}(2)$ is superior compared with $\mathrm{Eq}(1)$ and $\mathrm{Eq}(3)$ (see Table 6). All other investigated measures (see Table 6) sustain the model from $\operatorname{Eq}(3)$ as the most accurate model in estimation of the total strain energy on $\mathrm{C}_{40}$ fullerene congeners.

Table 6. Characteristic of the models from $\mathrm{Eq}(1)$ $\mathrm{Eq}(3)$ : estimation power

\begin{tabular}{|l|c|c|c|}
\hline \multicolumn{1}{|c|}{$\begin{array}{c}\text { Parameter } \\
\text { (Abbreviation) }\end{array}$} & Eq(1) & Eq(2) & Eq(3) \\
\hline $\begin{array}{l}\text { Residual Mean Square } \\
\text { (RMS) }\end{array}$ & 0.00114 & 0.00103 & 0.00098 \\
\hline $\begin{array}{l}\text { Average Prediction } \\
\text { Variance (APV) }\end{array}$ & 0.00125 & 0.00113 & 0.00108 \\
\hline $\begin{array}{l}\text { Average Prediction } \\
\text { Mean Squared Error } \\
\text { (APMSE) }\end{array}$ & 0.00003 & 0.00003 & 0.00003 \\
\hline $\begin{array}{l}\text { Mean Absolute Error } \\
\text { (MAE) }\end{array}$ & 0.1425 & 0.1409 & 0.1541 \\
\hline $\begin{array}{l}\text { Root Mean Square Error } \\
\text { (RMSE) }\end{array}$ & 0.0320 & 0.0304 & 0.0297 \\
\hline $\begin{array}{l}\text { Mean Absolute } \\
\text { Percentage Error } \\
\text { (MAPE) }\end{array}$ & 0.0050 & 0.0050 & 0.0055 \\
\hline $\begin{array}{l}\text { Standard Error of } \\
\text { Prediction (SEP) }\end{array}$ & 0.0324 & 0.0308 & 0.0301 \\
\hline $\begin{array}{l}\text { Relative Error of } \\
\text { Prediction (REP\%) }\end{array}$ & 0.1132 & 0.1074 & 0.1051 \\
\hline $\begin{array}{l}\text { Predictive Squares } \\
\text { Correlation Coefficient } \\
\left.\text { in Training Set (Q }{ }^{2} \mathrm{~F} 1\right)\end{array}$ & 0.9856 & 0.9870 & 0.9876 \\
\hline
\end{tabular}

\subsection{Assessment of prediction power}

Two different approaches were used to assess the prediction power of the models: the use of the weighted equations obtained on $\mathrm{C}_{40}$ fullerene dataset and the use of descriptors from $\mathrm{Eq}(1)-\mathrm{Eq}(3)$ models to predict the total strain energy using $\mathrm{C}_{42}$ dataset.

The same weight of 0.5 proved able to led to best fit of $\mathrm{Eq}(1)$ and $\mathrm{Eq}(2)$ on $\mathrm{C}_{42}$ congeners. The proper weight able to led to best fit of $\mathrm{Eq}(3)$ on $\mathrm{C}_{42}$ congeners proved equal to 0.1 .

The SMPI descriptors from the best performing models identified on $\mathrm{C}_{40}(\mathrm{n}=40)$ congeners were used as independent variable to predict total strain energy on $\mathrm{C}_{42}$ congeners $(\mathrm{n}=45)$ and the results are presented in $\mathrm{Eq}(4)-(6)$ :

$$
\begin{aligned}
& \hat{\mathrm{Y}}=2.62 \times 10^{3}+0.0004 * \text { ImUGG- } \\
& 6.09 \times 10^{5 * \mathrm{RJUGE}-} \\
& 2.3287 * \text { IFEGE }+3.22 \times 10^{-4 *} \text { IIEGA }
\end{aligned}
$$$$
\mathrm{r}^{2}=0.9591, \mathrm{r}^{2}{ }_{\text {adj }}=0.9550, \text { F-value }\left(\mathrm{p}=3.53 \times 10^{-27}\right)=
$$$$
234, \mathrm{Q}^{2}=0.9448
$$

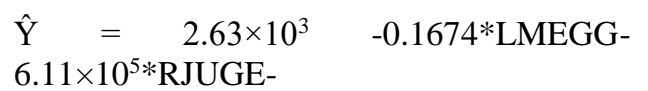

$2.3259 *$ IFEGE $+3.12 \times 10^{-4} *$ IIEGA

$\mathrm{r}^{2}=0.9585, \mathrm{r}^{2}{ }_{\text {adj }}=0.9543$, F-value $\left(\mathrm{p}=4.69 \times 10^{-27}\right)=$ $231, \mathrm{Q}^{2}=0.9453$

\section{$\hat{\mathrm{Y}}=2.4422 * \mathrm{IJUGE}+1.4432 *$ IFUGE \\ $2.5143 *$ IIUGE-0.4643*IIPTB}

$\mathrm{r}^{2}=0.9785, \mathrm{r}_{\text {adj }}^{2}=0.9526$, F-value $\left(\mathrm{p}=5.52 \times 10^{-33}\right)=$ $467, Q^{2}=0.9745$

where $\hat{Y}=$ estimated total strain energy; ImUGG, RJUGE, IFEGE, IIEGA, LMEGG, IJUGE, IFUGE, IIUGE, and IIPTB = SMPI structural descriptors; $\mathrm{r}^{2}$ $=$ determination coefficient; $r^{2}{ }_{\text {adj }}=$ adjusted determination coefficient $;$ F-value $=$ ratio of variance explained by the model; $p$-value $=p$-value associated to $\mathrm{F}$-value $\mathrm{Q}^{2}=$ determination coefficient in leaveone-out analysis.

The prediction metrics for both approaches are presented in Table 7. An analysis of Table 7 showed that the models that used the SMPI descriptors had better prediction abilities compared with the weighted Eq(1)-(3) models. Even if some of the weighted models had prediction abilities (see $\operatorname{Eq}(1)^{*} 0.5$, Table 7), the models from $\mathrm{Eq}(4)-(6)$ more accurate prediction powers.

Table 7. Prediction metrics on $\mathrm{C}_{42}$ congeners

\begin{tabular}{|l|l|l|l|l|l|l|l|}
\hline \multicolumn{1}{|c|}{ Model } & \multicolumn{1}{|c|}{$\mathbf{r}^{\mathbf{2}}{ }_{\text {ext }}$} & \multicolumn{1}{|c|}{$\mathbf{Q}^{\mathbf{2}} \mathbf{F}$} & \multicolumn{1}{|c|}{$\mathbf{Q}^{\mathbf{2}} \mathbf{F}$} & \multicolumn{1}{|c|}{ RMSEP } & \multicolumn{1}{|c|}{ MAEP } & \multicolumn{1}{c|}{ CCC [95\%CI] } & \%PredErr \\
\hline $\mathrm{Eq}(1) * 0.5$ & 0.5251 & 0.6249 & 0.6673 & 0.9225 & 0.7744 & $0.7031[0.6060-0.7795]$ & 1.12 \\
\hline $\mathrm{Eq}(4)$ & 0.9591 & 0.9591 & 0.9713 & 0.2708 & 0.2129 & $0.9791[0.9624-0.9884]$ & 0.31 \\
\hline $\mathrm{Eq}(2) * 0.5$ & $\mathrm{NR}$ & 0.3457 & $\mathrm{NR}$ & 1.3386 & 2.7387 & $0.1991[0.1296-0.2667]$ & 3.96 \\
\hline $\mathrm{Eq}(5)$ & 0.9585 & 0.9585 & 0.9709 & 0.2728 & 0.2172 & $0.9788[0.9620-0.9882]$ & 0.31 \\
\hline $\mathrm{Eq}(3) * 0.1$ & 0.6143 & $\mathrm{NR}$ & $\mathrm{NR}$ & 1.3386 & 1.7185 & $0.1663[0.1063-0.2251]$ & 2.49 \\
\hline $\mathrm{Eq}(6)$ & 0.9785 & 0.9785 & 0.9850 & 0.1962 & 0.1544 & $0.9891[0.9803-0.9940]$ & 0.22 \\
\hline
\end{tabular}

$\mathrm{r}^{2}{ }_{\mathrm{ext}}=$ determination coefficient of the prediction set; $\mathrm{Q}^{2} \mathrm{~F} 2=$ predictive square correlation coefficient in external set;

$\mathrm{Q}^{2} \mathrm{~F} 3=$ external predictive ability; $\mathrm{RMSEP}=$ root means square error of predicted;

MAEP = mean absolute error of predicted; \%PredErr = percentage predictive error;

CCC $[95 \% \mathrm{CI}]=$ concordance correlation coefficient $[$ two-sided $95 \%$ confidence intervals]; $\mathrm{NR}=$ not reliable value 
The plots associated with the applied approaches are presented in Figure 2. The analysis of the graphical representations of the models leads to the same conclusion as the analysis of the prediction metrics presented in Table 7. These lead to the conclusion that SMPI descriptors belonging to the most accurate estimation models to fit total strain energy on $\mathrm{C}_{40}$ congeners are also able to fit the total strain energy on $\mathrm{C}_{42}$ congeners. Similar results are expected to be seen also on other similar sets of $C_{n}$ congeners.

The model with four descriptors showed abilities in estimation (on $\mathrm{C}_{40}$ dataset) and prediction (on $\mathrm{C}_{42}$ dataset). The best prediction is obtained when the descriptors identified to belong to the most accurate models on $\mathrm{C}_{40}$ congeners are used to predict the same property, namely total strain energy, on $\mathrm{C}_{42}$ congeners. This result is similar with the previously reported results [18]. The analysis of $\mathrm{Eq}(3)$ and $\mathrm{Eq}(4)$ showed lower values of the coefficients in prediction model compared with estimation model but without any change of the sign (as + or -) of the coefficients. According with this model, the total strain energy of $\mathrm{C}_{40}$ and $\mathrm{C}_{42}$ fullerene congeners is explained by electronegativity and atomic number as atomic property of the compounds, having geometric and topologic component. One of the fourth descriptors seen in the most accurate model, namely IJUGE, was also identified as descriptor linked with the total strain energy in the previously reported study on $\mathrm{C}_{42}$ congeners [18].
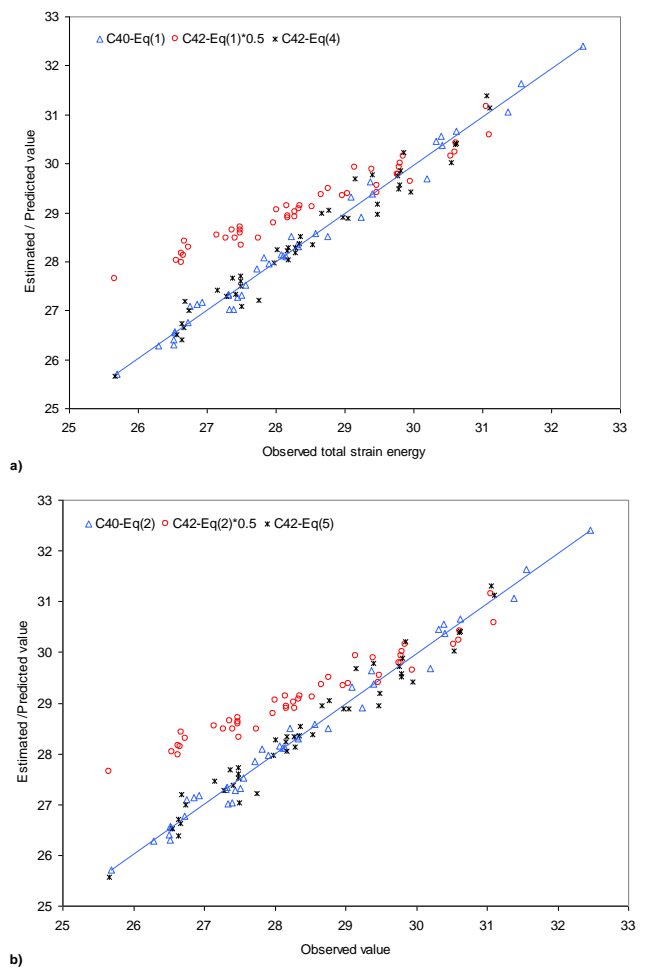

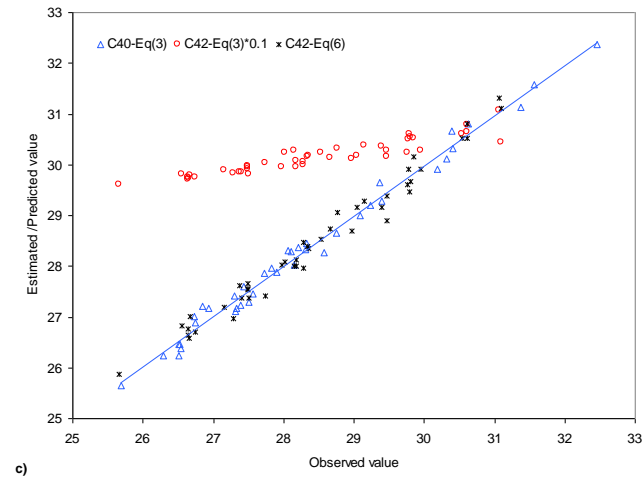

Figure 2. The fit between observed total strain energy and estimated TSE values by the models: a) $\mathrm{Eq}(1)$ on $\mathrm{C}_{40} \& \mathrm{Eq}(1) * 0.5$ on $\mathrm{C}_{42}$ and $\mathrm{Eq}(4)$ on $\mathrm{C}_{42}$, b) $\mathrm{Eq}(2)$ on $\mathrm{C}_{40} \& \mathrm{Eq}(2)^{*} 0.5$ on $\mathrm{C}_{42}$ and $\mathrm{Eq}(5)$ on $\left.\mathrm{C}_{42}, \mathrm{c}\right) \mathrm{Eq}(3)$ on $\mathrm{C}_{40} \& \mathrm{Eq}(3)^{*} 0.1$ on $\mathrm{C}_{42}$ and $\mathrm{Eq}(6)$ on $\mathrm{C}_{42}$

\subsection{Comparison with other reported models}

A regression model is considered to have prediction power if is accurate on compounds not included in the dataset on which the model was obtained. The prediction power of regression models was tested on external data set represented by $\mathrm{C}_{42}$ fullerene isomers in this manuscript and the model in $\mathrm{Eq}(5)$ and $\mathrm{Eq}(6)$ proved accurate models. However, are the models given by Eq(5) and Eq(6) different by the more accurate models obtained on $C_{42}$ fullerene isomers? To test this, the models in $\mathrm{Eq}(5)$ and $\mathrm{Eq}(6)$ were compared in regard of goodness-of-fit with two previously reported models [18] using Steiger's correlated correlation analysis [28].

The most accurate models reported on $\mathrm{C}_{42}$ fullerene isomers able to estimate and predict the total strain energy using SMPI descriptor as previously reported [18] are as follow:

$$
\begin{aligned}
& \hat{\mathrm{Y}}= \\
& 3 * \mathrm{IIUGF}+2.16 * \text { IJUGE }
\end{aligned}
$$

$\mathrm{r}^{2}=0.9836, \mathrm{r}_{\text {adj }}^{2}=0.9824$, F-value $\left(\mathrm{p}=1.30 \times 10^{-36}\right)=$ $820, \mathrm{Q}^{2}=0.9809, \%$ PredErr $=19.76$

$$
\begin{aligned}
& \hat{Y}=-199.61-21.63 * \text { IFETB+40.90*IFUGB- } \\
& 2.62 \times 10-3 * \text { IIUGF+1.56*IJUGE }
\end{aligned}
$$

$\mathrm{r}^{2}=0.9898, \mathrm{r}_{\text {adj }}^{2}=0.9888$, F-value $\left(\mathrm{p}=2.87 \times 10^{-39}\right)=$ 974, $\mathrm{Q}^{2}=0.9768, \%$ PredErr $=15.95$

No significant difference in regard of correlation coefficients was observed when Eq(7) was compared with $\mathrm{Eq}(8)$ (Table 8). All other cases showed significant higher correlation coefficients as the number of equation increased (Table 8).

Table 8. Correlated correlation analysis: p-value matrix for comparisons amongst $\mathrm{Eq}(5)$ to $\mathrm{Eq}(7)$

\begin{tabular}{|l|l|l|l|}
\hline & $\mathrm{Eq}(6)$ & $\mathrm{Eq}(7)$ & $\mathrm{Eq}(8)$ \\
\hline $\mathrm{Eq}(5)$ & 0.0001 & 0.0001 & $5.69 \cdot 10^{-8}$ \\
\hline $\mathrm{Eq}(6)$ & & $3.08 \cdot 10^{-11}$ & $1.12 \cdot 10^{-14}$ \\
\hline $\mathrm{Eq}(7)$ & & & 0.0705 \\
\hline
\end{tabular}


An analysis of models given by $\mathrm{Eq}(5)-\mathrm{Eq}(8)$ and of the results presented in Table 8 reveals the following:

- At least one SMPI descriptor is the same in $\operatorname{Eq}(5)$ and $\mathrm{Eq}(7)$, and $\mathrm{Eq}(6)$ and $\mathrm{Eq}(8)$, respectively

- $\quad$ The model with four descriptors in $\mathrm{Eq}(8)$ has an intercept significantly different by zero compared with the model in $\mathrm{Eq}(6)$ that proved an intercept not significantly different by zero

- The explanatory power express by $\mathrm{r}^{2}$ is higher on models from $\mathrm{Eq}(7)$ and $\mathrm{Eq}(8)$ compared with models on $\operatorname{Eq}(5)$ and $\operatorname{Eq}(6)$

- No difference in regard of goodness-of-fit is observed between $\mathrm{Eq}(7)$ and $\mathrm{Eq}(8)$.

The results of our study showed that the SMPI descriptors accurately fit the total strain energy on $\mathrm{C}_{40}$ isomers. Nevertheless, the SMPI descriptors able to explain the total strain energy of $\mathrm{C}_{40}$ fullerene isomers provide fair models also on $\mathrm{C}_{42}$ fullerene congeners.

Even if fair prediction power was obtained on $\mathrm{C}_{42}$ fullerene congeners, the goodness-of-fit is lower compared with the goodness-of-fit of the most accurate models previously reported on $\mathrm{C}_{42}$ fullerene isomers. Furthermore, differences are observed in atomic properties and the contribution of topology and/or geometry to the total strain energy are observed when the model is constructed on the $\mathrm{C}_{42}$ fullerene isomers compared with the approach when the model constructed on $\mathrm{C}_{40}$ fullerene congeners is used to predict the total strain energy.

\section{Conclusions}

Estimation of properties with families of descriptors derived from structure is generally superior to estimation of the properties from other properties. In fact, it is a hazard to predict one property from another since the properties are measured in different conditions and/or with different instrumentation, or are calculated using different formulas and/or approaches).

The total strain energy was successfully model on $\mathrm{C}_{40}$ fullerene isomers and those structural characteristics able to explain the variation of total strain energy were identified. A model with four descriptors proved most accurate model and show fair abilities in prediction of the same property on $\mathrm{C}_{42}$ fullerene isomers when the approach considered the descriptors identified on $\mathrm{C}_{40}$ as the input descriptors for $\mathrm{C}_{42}$ fullerene isomers.

\section{Conflict of interests}

The authors declare that there is no conflict of interests.

\section{References}

[1]. O. Kharlamov, G. Kharlamova, N. Kirillova, O. Khyzhun, and V. Trachevskii, NATO Science for Peace and Security Series A: Chemistry and Biology 245 (2012)

[2]. P. Peng, F.-F. Li, F. L. Bowles, V. S. P. K. Neti, A. J. Metta-Magana, M. M. Olmstead, A. L. Balch, and L. Echegoyen, Chem. Commun. 49, 3209 (2013).

[3]. J. Pattanayak, T. Kar, and S. Scheiner, J. Phys. Chem. A 108, 7681 (2004).

[4]. E. E. Maroto, M. Izquierdo, S. Reboredo, J. Marco-Martínez, S. Filippone, and N. Martín, Acc. Chem. Res. 47, 2660 (2014).

[5]. E. Ulloa, Fullerenes and their Applications in Science and Technology [online] [accessed on 28th of November 2015]. Available from: http://web.eng.fiu.edu/ vlassov/EEE5425/Ulloa-Fullerenes.pdf

[6]. C. B. Nielsen, S. Holliday, H.-Y. Chen, S. J. Cryer, and I. McCulloch, Acc. Chem. Res. 48, 2803 (2015)

[7]. W. Fa, S. Chen, S. Pande, and X. Cheng Zeng, J. Phys. Chem. A 119, 11208 (2015).

[8]. D. Bakowies and W. Thiel, J. Am. Chem. Soc. 13, 3704 (1991).

[9]. G. B. Adams, M. O'Keefe, and R. S. Ruoff. J. Phys. Chem. 98, 9465 (1994).

[10]. G. Ying-Duo, and W. C. Herndon, J. Am. Chem. Soc. 115, 8459 (1993)

[11]. J. Xiao, M. Li, Y.-N. Chiu, M. Fu, S.-T. Lai, and N. N. Li, J. Mol. Struct. 428, 149 (1998).

[12]. R. Salcedo, and L. E. Sansores, J. Mol. Struct. 422, 245 (1998).

[13]. X. Yang, G. Wang, Z. Yang, Z. Shang, Z. Cai, Y. Pan, B. Wu, and X. Zhao, J. Mol. Struct. 579, 91 (2002).

[14]. M. F. Dinca, S. Ciger, M. Ştefu, F. Gherman, K. Miklos, C. Nagy, O. Ursu, and M. V. Diudea, Carpathian J. Math. 20, (2004).

[15]. A. A. Hindi and A. A. El-Barbary, J. Mol. Struct. 1080, 169 (2015).

[16]. A. Kerim, J. Phys. Org. Chem. 25, 379 (2012).

[17]. L. Jäntschi [online] 2014 [accessed August 3, 2015] Szeged Matrix Property Indices. URL: http://l.academicdirect.org/Chemistry/SARs/SM PI

[18]. S. D. Bolboacă and L. Jäntschi, J. Chem. 2016, Article ID 1791756 (2016).

[19]. S. L. Mayo, B. D. Olafson, and W. A. Goddard, J. Phys. Chem. 94, 8897 (1990).

[20]. M. J. S. Dewar, E. G. Zoebisch, H. F. Eamonn, and J. J. P. Stewart, J. Am. Chem. Soc. 107, 3902 (1985).

[21]. S. D. Bolboacă, L. Jäntschi, and M. V. Diudea, Curr. Comput. Aided Drug Des. 9, 195 (2013).

[22]. S. D. Bolboacă and L. Jäntschi, Environ. Chem. Lett. 6, 175 (2008).

[23]. S. D. Bolboacă and L. Jäntschi, BIOMATH 2, 
1309089 (2013).

[24]. S. D. Bolboacă and L. Jäntschi, Combin. Chem. High Throughput Screen. 16, 288 (2013).

[25]. N. Chirico and P. Gramatica, J. Chem. Inf. Model 52, 2044 (2012).

[26]. L. Pauling, J. Am. Chem. Soc. 54, 3570 (1932).

[27]. A. L. Allred, J. Inorg. Nucl. Chem. 17, 215
(1961).

[28]. J. H. Steiger, Psychol. Bull. 87, 245 (1980).

Received: 18.04 .2016

Received in revised form: 04.07.2016

Accepted: 20.07.2016 